\title{
Update on Changing Terminologies in Sepsis
}

\author{
Simalti $\mathbf{A}^{1}$, Ghuliani $\mathbf{R}^{2}$, Nair $\mathbf{B T}^{3}$
}

${ }^{1}$ Dr. Ashish Kumar Simalti, MBBS, MD, FNB Paediatric Critical Care, Pediatric Intensivist, Base Hospital, New Delhi, '2Dr. Ranjit Ghuliani, MBBS, MD. Consultant and Head of Department of Paediatrics, Base Hospital, New Delhi, India, ${ }^{3} \mathrm{Dr}$. Bindu T Nair, MBBS, MD. Associate Professor, Department of Paediatrics, Army College of Medical Sciences, New Delhi, India.

Address for correspondence:

Dr. Ashish Simalti

E-mail: ashishsimalti@rediffmail.com

\section{How to cite}

Simalti A, Ghuliani R, Nair BT. Update on Changing Terminologies in Sepsis. J Nepal Paediatr Soc 2016;36(2):178-183.

doi: http://dx.doi.org/10.3126/jnps.v36i2.14884

This work is licensed under a Creative Commons Attribution 3.0 License.

\section{(c) (P)}

\section{Introduction}

$\mathrm{D}_{\mathrm{t}}$

\begin{abstract}
Definitions of sepsis and septic shock were last revised in 2001. Since then there have been considerable advances in our understanding of pathophysiology, management, and epidemiology of sepsis, suggesting the need for reexamination. The European Society of Intensive Care Medicine and the Society of Critical Care Medicine convened a task force in January 2014 with objective to evaluate and, as needed, update definitions for sepsis and septic shock. Recommendations of this task force were published recently as "The Third International Consensus Definitions for Sepsis and Septic Shock (Sepsis-3)". The aim of this article is to generate awareness and discussion regarding this new important development.
\end{abstract}

Key words: Sepsis, Septic shock, SIRS, qSOFA efinition of sepsis and septic shock are revised from time to time ${ }^{1}$. Aim of this article is to generate awareness and discussion regarding latest recommendations labelled as Sepsis $3^{2}$. Our understanding of sepsis has been constantly evolving from early description of fever and significance of core periphery temperature difference by Hippocrates to observation by William Osler that the patients die from the body's response to an infection rather than from the infection itself $f^{3,4}$. In 1991, a consensus conference was held with purpose of developing definitions for sepsis to bring uniformity among clinicians. During that time primary focus was on host's systemic inflammatory response syndrome (SIRS) to infection. Sepsis complicated by organ dysfunction was termed severe sepsis, which could progress to septic shock, defined as "sepsis-induced hypotension persisting despite adequate fluid resuscitation". In 2001 these definitions were examined and found to have limitations for example the excessive focus on inflammation, the misleading model that sepsis follows a continuum through severe sepsis to shock, and inadequate specificity and sensitivity of the systemic inflammatory response syndrome (SIRS) criteria. However no alternatives were suggested as ample supporting evidence was lacking to develop alternate concepts and definitions ${ }^{1}$. Currently, infection is considered a trigger for sepsis and to eliminate subjectivity in differentiating simple infection from sepsis, it is important to develop criteria for 
the same. As the syndrome of sepsis does not have specific diagnostic test(s) which can be considered gold standard, it leads to significant variations in reported incidence and mortality rates besides impacting early recognition and management. Mariansdatter et al studied 23 publications reporting incidence of sepsis and found that reported incidence ranged from 74 to 1180 per 100,000 person-years. This wide range was attributed to differences in the method used to collect the data, the study period, or the world region where the study was undertaken ${ }^{5}$. Aim of this taskforce was to bring uniformity as well as practicality in identifying sepsis accurately in any single patient as well as overall population.

\section{Challenges}

As per evolving understanding, dysregulated host response differentiates sepsis from infection and causes organ dysfunction. No gold standard diagnostic test(s) exists which can identify sepsis because it is not a specific illness but rather a syndrome consisting of some common signs and symptoms. Concept of SIRS was challenged by this task force as sepsis is no longer considered simply systemic inflammatory response as it also involves anti-inflammatory responses like upregulated expression of inhibitory receptors including PD1, expansion of T regulatory (Treg) cell and myeloidderived suppressor cell (MDSC) populations ${ }^{6}$. Besides it was argued that existing SIRS criteria were present in many hospitalized patients without a dysregulated response and they did not predict adverse outcome. Response of cardiovascular, neuronal, autonomic, hormonal, bioenergetic, metabolic and coagulation systems are now considered to be integral in progression of sepsis and are of prognostic significance ${ }^{7,8,9}$. Significant biological and clinical heterogeneity exists in affected individuals ${ }^{10}$. Factors like age, underlying co-morbidities, concurrent injuries including surgeries and medications and source of infection also determine which subset of population will progress to sepsis and shock following infection ${ }^{11}$. In future with better understanding of genetics and molecular biology this subset may be better characterized and identified early. Another challenge taken into consideration was as how to differentiate non-infectious insults such as trauma or pancreatitis from sepsis ${ }^{12}$. It was noted that there was significant heterogeneity in reported mortality from septic shock which could reflect heterogeneity of data collection and interpretation because of lack of consistency of definition and unavailability of a gold standard test as mentioned above. To reduce interobserver variability while monitoring a patient with organ dysfunction, various scoring systems based on clinical findings, laboratory data, or therapeutic interventions have been proposed from time to time. Examples include Therapeutic Intervention Scoring System (TISS), The Acute Physiology and Chronic Health Evaluation (APACHE) system, Physiologic Stability Index (PSI), Pediatric Risk Of Mortality (PRISM). These scores are well validated in PICU environments but require a lot of data collection (as shown in table below for PRISM). This limits use of these scoring systems among nonintensivists. Attempts to reducing variables to be recorded in order to make them more practical have led to loss of predictive value hence utility of these scores ${ }^{13}$. Similarly there are many disease-specific or conditionspecific clinical scores to aid in the evaluation of severity of illness, prognosis, pathophysiological understanding, or therapeutic needs like croup score, Glasgow coma score (GCS) etc.

\section{Selection of clinical criteria to identify sepsis and septic Shock}

The task force evaluated which clinical criteria best identified infected patients most likely to have sepsis. This objective was achieved by interrogating large data sets of hospitalized patients with presumed infection, assessing agreement among existing scores of inflammation (SIRS) ${ }^{5}$ or organ dysfunction ${ }^{14}$ (e.g., SOFA, Logistic Organ Dysfunction System) (construct validity), and delineating their correlation with subsequent outcomes (predictive validity). In addition, multivariable regression was used to explore the performance of 21 bedside and laboratory criteria proposed by the 2001 task force ${ }^{1}$. To define septic shock, following terms were selected and examined viz "hypotension," "need for vasopressor therapy," "raised lactate," and "adequate fluid resuscitation". Lactate levels above $2 \mathrm{mmol} / \mathrm{L}$ and $4 \mathrm{mmol} / \mathrm{L}$ were examined separately for their sensitivity and specificity. Mean arterial pressure less than $65 \mathrm{mmHg}$ was taken as hypotension as this was most often recorded in data sets derived from adult patients with sepsis. Systolic blood pressure was used as a qSOFA criterion because it was most widely recorded in the electronic health record data sets. These criteria were tested in various databases namely Surviving Sepsis Campaign's International Multicenter Registry, University of Pittsburgh Medical Center and Kaiser Permanente Northern California. 
Table 1: Terminology and International Classification of Diseases Coding ${ }^{2}$

\begin{tabular}{|c|c|c|}
\hline $\begin{array}{l}\text { Current Guidelines } \\
\text { and Terminology }\end{array}$ & Sepsis & Septic Shock \\
\hline $\begin{array}{l}1991 \text { and } 2001 \text { consensus } \\
\text { terminology }\end{array}$ & $\begin{array}{l}\text { Severe sepsis } \\
\text { Sepsis-induced } \\
\text { hypoperfusion }\end{array}$ & Septic shock \\
\hline 2015 Definition & $\begin{array}{l}\text { Sepsis is life-threatening } \\
\text { organ dysfunction caused by a } \\
\text { dysregulated host response to } \\
\text { infection }\end{array}$ & $\begin{array}{l}\text { Septic shock is a subset of sepsis in } \\
\text { which underlying circulatory and cellular/ } \\
\text { metabolic abnormalities are profound } \\
\text { enough to substantially increase mortality }\end{array}$ \\
\hline $\begin{array}{l}2015 \text { Clinical } \\
\text { criteria }\end{array}$ & $\begin{array}{l}\text { Suspected or documented } \\
\text { infection and an acute increase } \\
\text { of } \geq 2 \text { SOFA points (a proxy for } \\
\text { organ dysfunction) }\end{array}$ & $\begin{array}{l}\text { Sepsis and vasopressor therapy needed } \\
\text { to elevate } \mathrm{MAP} \geq 65 \mathrm{~mm} \mathrm{Hg} \text { and lactate }>2 \\
\mathrm{mmol} / \mathrm{L}(18 \mathrm{mg} / \mathrm{dL} \text { ) despite adequate fluid } \\
\text { resuscitation }\end{array}$ \\
\hline \multicolumn{3}{|l|}{ Recommended primary ICD codes } \\
\hline ICD-9 & 995.92 & 785.52 \\
\hline ICD-10 & R65.20 & $\mathrm{R} 65.21$ \\
\hline $\begin{array}{l}\text { Framework for implementation } \\
\text { for coding and research }\end{array}$ & \multicolumn{2}{|c|}{$\begin{array}{l}\text { Identify suspected infection by using concomitant orders for blood cultures and } \\
\text { antibiotics (oral or parenteral) in a specified period } \\
\text { Within specified period around suspected infection: } \\
\text { 1. Identify sepsis by using a clinical criterion for life-threatening organ } \\
\text { dysfunction } \\
\text { 2. Assess for shock criteria, using administration of vasopressors, MAP <65 } \\
\mathrm{mm} \mathrm{Hg} \text {, and lactate }>2 \mathrm{mmol} / \mathrm{L}(18 \mathrm{mg} / \mathrm{dL})\end{array}$} \\
\hline
\end{tabular}

Table 2: Sequential [Sepsis-Related] Organ Failure Assessment Score (for adults) ${ }^{2}$

\begin{tabular}{|c|c|c|c|c|c|}
\hline System & Score & & & & \\
\hline & 0 & 1 & 2 & 3 & 4 \\
\hline $\begin{array}{l}\text { Respiration } \\
\mathrm{PaO} 2 / \mathrm{FIO} 2, \mathrm{mmHg}(\mathrm{kPa})\end{array}$ & $\begin{array}{l}\geq 400 \\
(53.3)\end{array}$ & $<400(53.3)$ & $<300(40)$ & $\begin{array}{l}<200(26.7) \text { with } \\
\text { respiratory support }\end{array}$ & $\begin{array}{l}<100(13.3) \text { with } \\
\text { respiratory support }\end{array}$ \\
\hline $\begin{array}{l}\text { Coagulation } \\
\text { Platelets, } \times 10^{3} / \mu \mathrm{L}\end{array}$ & $\geq 150$ & $<150$ & $<100$ & $<50$ & $<20$ \\
\hline $\begin{array}{l}\text { Liver } \\
\text { Bilirubin, mg/dL } \\
(\mu \mathrm{mol} / \mathrm{L})\end{array}$ & $\begin{array}{l}<1.2 \\
(20)\end{array}$ & $\begin{array}{l}1.2-1.9(20- \\
32)\end{array}$ & $2.0-5.9(33-101)$ & $6.0-11.9(102-204)$ & $>12.0(204)$ \\
\hline Cardiovascular & $\begin{array}{l}\text { MAP } \\
\geq 70 \\
\mathrm{~mm} \mathrm{Hg}\end{array}$ & $\begin{array}{l}\mathrm{MAP}<70 \\
\mathrm{~mm} \mathrm{Hg}\end{array}$ & $\begin{array}{l}\text { Dopamine }<5 \text { or } \\
\text { dobutamine (any } \\
\text { dose) }\end{array}$ & $\begin{array}{l}\text { Dopamine } 5.1-15 \\
\text { or epinephrine } \leq 0.1 \\
\text { or norepinephrine } \leq 0.1\end{array}$ & $\begin{array}{l}\text { Dopamine }>15 \text { or } \\
\text { epinephrine }>0.1 \\
\text { or norepinephrine } \\
>0.1\end{array}$ \\
\hline \multicolumn{6}{|l|}{ Central nervous system } \\
\hline $\begin{array}{l}\text { Glasgow Coma Scale } \\
\text { score }\end{array}$ & 15 & $13-14$ & $10-12$ & $6-9$ & $<6$ \\
\hline $\begin{array}{l}\text { Renal } \\
\text { Creatinine, mg/dL } \\
(\mu \mathrm{mol} / \mathrm{L})\end{array}$ & $\begin{array}{l}<1.2 \\
(110)\end{array}$ & $\begin{array}{l}1.2-1.9 \\
(110-170)\end{array}$ & $\begin{array}{l}2.0-3.4 \\
(171-299)\end{array}$ & $\begin{array}{l}3.5-4.9 \\
(300-440)\end{array}$ & $\begin{array}{l}>5.0 \\
(440)\end{array}$ \\
\hline Urine output, $\mathrm{mL} / \mathrm{d}$ & & & & $<500$ & $<200$ \\
\hline
\end{tabular}




\section{Box 1. New Terms and Definitions as per new guidelines. Sepsis $-3^{2}$}

- Sepsis is defined as life-threatening organ dysfunction caused by a dysregulated host response to infection.

- Organ dysfunction can be identified as an acute change in total SOFA score>2 points consequent to the infection.

- The baseline SOFA score can be assumed to be zero in patients not known to have preexisting organ dysfunction.

- A SOFA score of $>2$ reflects an overall mortality risk of approximately $10 \%$ in a general hospital population with suspected infection. Even patients presenting with modest dysfunction can deteriorate further, emphasizing the seriousness of this condition and the need for prompt and appropriate intervention, if not already being instituted.

- In lay terms, sepsis is a life-threatening condition that arises when the body's response to an infection injures its own tissues and organs.

- Patients with suspected infection who are likely to have a prolonged ICU stay or to die in the hospital can be promptly identified at the bedside with qSOFA, i.e., alteration in mental status, systolic blood pressure $<100 \mathrm{mmHg}$, or respiratory rate $>22 / \mathrm{min}$.

- Septic shock is a subset of sepsis in which underlying circulatory and cellular/metabolic abnormalities are profound enough to substantially increase mortality.

- Patients with septic shock can be identified with a clinical construct of sepsis with persisting hypotension requiring vasopressors to maintain MAP at $65 \mathrm{mmHg}$ and having a serum lactate level $>2 \mathrm{mmol} / \mathrm{L}(18 \mathrm{mg} / \mathrm{dL})$ despite adequate volume resuscitation. With these criteria, hospital mortality is in excess of $40 \%$.

Abbreviations: MAP, mean arterial pressure; qSOFA, quick SOFA;

SOFA: Sequential [Sepsis-related] Organ Failure Assessment.

\section{Recommendations}

Sepsis is defined by this task force as a "syndrome shaped by pathogen factors and host factors with characteristics that evolve over time." This has been labelled as Sepsis-3 to differentiate it from previous definitions. (Box 1). The task force has also suggested how the new definitions can be applied in current ICD system (Table 2). For general public, task force has endorsed existing definition which says "Sepsis is a life-threatening condition that arises when the body's response to infection injures its own tissues"15. Widespread educational campaigns are recommended to better inform the public that sepsis may portend death, especially if not recognized early and treated promptly.

Recognition of organ dysfunction merits a prompt and appropriate response as it is associated with inhospital mortality in excess of $10 \%$. In view of this severe sepsis terminology is removed with the recommendation that any degree of sepsis should warrant greater levels of monitoring and intervention, including possible admission to critical care or high dependency facilities. The 2001 task force had noted that many bedside examination findings and routine laboratory test results are indicative of inflammation or organ dysfunction ${ }^{1}$. This task force evaluated which clinical criteria best identified infected patients most likely to have sepsis. This was based on 44 studies involving 166,479 patients. Criteria were selected by statistical methods including univariate, multivariate studies and logistic regression. Later Delphi process identified 3 significant criteria (hypotension, serum lactate level, and vasopressor therapy) alone or in combination in differentiating sepsis from infection and predicting mortality ${ }^{16}$.

\section{Need for having specific age based criteria for Paediatrics}

Most of the understanding about sepsis has been derived from adult studies. However age and size dependent variability of physiological parameters and relatively low pediatric mortality compared to adults make implementation of these studies difficult. Mortality among children secondary to pneumonia, diarrhoea, malaria, and other infectious diseases used to be very high few decades ago. This has been significantly reduced by early identification and timely management of sepsis in these cases. Incidence of sepsis in population below 19 years was estimated to be 0.56 cases per 1000 population annually with mortality at $\sim 10 \%$ for all age groups ${ }^{17}$. As care becomes more standardized across PICUs it becomes important to have uniform criteria to enable paediatricians all over to incorporate new developments and compare results. Lots of research is ongoing in pediatric sepsis which is based on re-establishing equilibrium between pro and anti inflammatory limbs. Some of the examples are ethyl pyruvate ${ }^{18}$ and pentoxifylline, to reduce proinflammatory cytokine production in endotoxemia and high-mobility gene box 1 (HMGB1) protein neutralizing antibodies ${ }^{19}$. Uniform criteria are a must for collaborative interventional trials for all these ongoing exciting therapies in PICUs. 


\section{Sequential Organ Failure Assessment (SOFA)}

For objective monitoring and inter institute comparison of database in cases of sepsis with organ dysfunction, Sepsis-related Organ Failure Assessment or Sequential Organ Failure Assessment (SOFA) (Table 3) was adopted by this task force because of its familiarity among intensivists ${ }^{13}$. Besides SIRS, different scores (SOFA, Logistic Organ Dysfunction System) were assessed for their ability to predict outcomes. An economical measure, termed qSOFA (for quick SOFA) which incorporated altered mentation, systolic blood pressure of $100 \mathrm{~mm} \mathrm{Hg}$ or less, and respiratory rate of $22 / \mathrm{min}$ or greater, was found to provide simple bedside criteria to identify adult patients with suspected infection and poor outcome (Box 2). Patients with a SOFA score of 2 or more had an overall mortality risk of approximately $10 \%$ in a general hospital population with presumed infection ${ }^{20}$. The task force recommended using a change in baseline of the total SOFA score of two points or more to represent organ dysfunction. Strengths of SOFA score include familiarity, validated relationship to mortality risk and it can even be recorded retrospectively because parameters used are monitored routinely as part of acute patient management. Concept of qSOFA could be a useful clinical tool, especially to physicians and other practitioners working outside the ICU. As qSOFA can be rapidly scored at the bedside without the need for blood tests, this score may be particularly relevant in resource-poor settings in which laboratory data are not readily available, and when the literature about sepsis epidemiology is sparse.

Box 2. qSOFA (Quick SOFA) Criteria ${ }^{2}$

Respiratory rate $>22 / \mathrm{min}$

Altered mentation

Systolic blood pressure $<100 \mathrm{mmHg}$

\section{Limitations}

Criteria selected are not all-encompassing and debate can be held as to which criteria should have been included and which ones do not provide additional benefit. Practical considerations such as ease of recording, reproducibility, objectivity and availability were taken into consideration while selecting criteria.
One important limitation is that some laboratory parameters like creatinine or bilirubin levels may not capture dysfunction early enough and novel biomarkers may be required to be incorporated after validation in later updates. Therapeutic interventions may improve the cardiovascular score and may underestimate state of organ dysfunction. The task force focused on adult patients but commented on the need to develop similar updated definitions for pediatric populations. The Task Force has to define for pediatric population use of clinical criteria that take into account their age dependent variations in normal physiologic ranges and also in pathophysiologic responses. These scores have been validated in database of US and need to be tested on the data collected in resource poor settings. Elevated lactate levels represent an important marker of "cryptic shock" in the absence of hypotension. Because of nonavailability of lactate measurement in resource-poor settings, it is not included in the scoring system. This is a major limitation considering growing importance of serial lactate monitoring in septic shock management. When qSOFA or SOFA are used as entry criteria for clinical trials there may be a conflict with existing scoring system which will require interrogation of data from large patient populations. As culture-positive "sepsis" is observed in only $30 \%$ to $40 \%$ of cases, epidemiological studies use proxies such as antibiotic commencement or a clinically determined probability of infection which is not very specific or objective. Definition of infection and identification of infection by microbiological means were not part of the task for this team, hence were left unchanged.

\section{Conclusion}

There are some significant changes in the concept of sepsis with less emphasis on inflammation as sole marker for sepsis. The task force has tried to bring objectivity in monitoring for organ dysfunction. It has followed the trend of software update system by calling these recommendations as Sepsis 3 which also says that these recommendations are no way final and will require further updates with further improvement in our understanding of what causes progression from infection to sepsis and what is the earliest stage where we can identify and act against it. 


\section{References}

1. Levy MM, Fink MP, Marshall JC et al. International Sepsis Definitions Conference. 2001 SCCM/ESICM IACCPIATS/SIS. International Sepsis Definitions Conference. Inten Care Med 2003; 29(4):530-38.

2. Singer M, Deutschman C S, Seymour $C W$ et al. Third International Consensus Definitions for Sepsis and Septic Shock (Sepsis-3). JAMA 2016; 315(8):801-10.

3. Funk DJ, Parrillo JE, Kumar A. Sepsis and septic shock: a history. Crit Care Clin 2009;31;25(1):83-101.

4. Hommes T J, Wiersinga W J, Poll T V. The Host Response to Sepsis. Yearbook of Intensive Care and Emergency Medicine 2009;1:39-50

5. Mariansdatter SE, Eiset AH, Søgaard KK, Christiansen CF. Sepsis incidence in the general population and its predictors: a literature review. In 26th European congress of clinical microbiology and infectious diseases 2016.

6. Hotchkiss RS, Monneret G, Payen D. Sepsis-induced immunosuppression: from cellular dysfunctions to immunotherapy. Nat Rev Immunol 2013;13(12):86274.

7. Angus DC, van der Poll T. Severe sepsis and septic shock. N Engl J Med. 2013;369(9):840-51.

8. Deutschman CS, Tracey KJ. Sepsis: current dogma and new perspectives. Immunity 2014;40 (4):463-75.

9. Singer $M$, De Santis V, Vitale $D$, JeffcoateW. Multiorgan failure is an adaptive, endocrine mediated, metabolic response to overwhelming systemic inflammation. Lancet 2004;364(9433):545-48.

10. Kwan A, Hubank M, Rashid A, Klein N, Peters MJ. Transcriptional instability during evolving sepsismay limit biomarker based risk stratification. PLoS One 2013;8(3):e60501.

11. Iskander KN, Osuchowski MF,Stearns-Kurosawa DJ, et al. Sepsis: multiple abnormalities, heterogeneous responses, andevolving understanding. Physiol Rev 2013;93(3):1247-88.

12. Chan JK, Roth J, Oppenheim JJ,et al. Alarmins: awaiting a clinical response. J Clin Invest 2012;122(8):2711-19.

13. Bhadoria P, Bhagwat AG. Severity scoring systems in paediatric intensive care units. Indian $J$ Anaesth 2008;52(5):663-75.

14. Vincent JL, Moreno R, Takala $\mathrm{J}$ et al. Working Group on Sepsis-Related Problems of the European Society of Intensive Care Medicine. The SOFA (Sepsis-related Organ Failure Assessment) score to describe organ dysfunction/failure. Inten Care Med 1996;22(7):707-10.

15. Czura CJ. "Merinoff symposium 2010: sepsis"speaking with one voice. Mol Med 2011;17 (1-2):2-3.

16. Shankar-Hari M, Phillips GS, Levy $M L$ et al. Developing a New Definition and Assessing New Clinical Criteria for Septic Shock For the Third International Consensus Definitions for Sepsis and Septic Shock (Sepsis-3). JAMA 2016;315(8):775-87.

17. Watson RS, Carcillo JA, Linde-Zwirble WT, et al. The epidemiology of severe sepsis in children in the United States. Am J Respir Crit Care Med 2003;167:695-701.

18. Han $Y$, Englert JA, Yang $R$, et al. Ethyl pyruvate inhibits nuclear factor-kappaB-dependent signaling by directly targeting p65. J Pharmacol Exp Ther 2005;312:1097-105.

19. Yang $\mathrm{H}$, Ochani M, Li J, et al. Reversing established sepsis with antagonists of endogenous high-mobility group box 1. Proc Natl Acad Sci USA 2004;101:296301.

20. Seymour CW, Liu VX, Iwashyna TJ et al. Assessment of Clinical Criteria for Sepsis for the Third International Consensus Definitions for Sepsis and Septic Shock (Sepsis-3). JAMA 2016;315(8):762-74. 